\title{
Fluid-Structure Interaction (FSI) Modelling of Aquaculture Net Cage
}

\author{
O Myrli, H Khawaja* \\ UiT-The Arctic University of Norway, Tromsø, Norway
}

\begin{abstract}
The number of good sites for aquaculture farming in less exposed locations is limited. The trends now are that fish cages are increasing in both width and depth, as well as being used in more weather-exposed locations. As the net cages increase in size, so does the material costs. The design of the sea cages should be modified for safe and reliable use in remote offshore locations. Fish farms located in more exposed areas will be subject to more energetic waves and stronger currents, which will cause large net deformations. This is a challenge because fish welfare depends on a certain minimum volume within the net cage. Changing and maintaining net cages are some of the main expenses for fish farms. If the lifetime of the net cages is extended by introducing stronger, longer lasting materials, the overall costs of the nets can likely to be reduced.

The traditional nets are produced using nylon, but promising solid PET-wire designs have also been introduced to the aquaculture industry. In this paper, we investigate the use of polyurethane in aquaculture net cages, which is studied together with nylon and PET-wire. The study is carried out using fluid-structure interaction (FSI) simulation, computational fluid dynamics (CFD) weakly coupled with structure mechanics (FEM). ANSYS ${ }^{\circledR}$ software is employed in the study. We will look at the materials that show the most promising results for aquaculture purposes.
\end{abstract}

\section{INTRODUCTION}

Aquaculture net cage may date back to as early as the 1200s in some areas of Asia and is currently a major form of aquaculture in countries including Canada, Chile, Japan, Norway and Scotland, where it has been used mainly for salmonid farming. However, a wide variety of fish species are grown in cages today including seawater, freshwater and diadromous species. Today, therefore, cages are used worldwide in the sea, in lakes and in large rivers. However, the number of good sites for aquaculture farming in less exposed locations is limited. The trends now are that fish cages are increasing in both width and depth as well as being used in more weather-exposed locations. The design of the sea cages should be modified for safe and reliable use in more remote offshore locations. Fish farms located in more exposed areas will be subject to more energetic waves and stronger currents, which will cause large net deformations. This is a challenge because fish welfare depends on a certain minimum volume within the net cage. In open production units in the sea there will always be possibilities for fish escape as a result of construction failure. The weather is unpredictable 
and large waves can result in breakage of the production unit. The material strength of net panels exposed to sunlight (UV), wind, rain, acid rain, etc. is reduced. This process is called weathering. To test the lifetime of the nets, you could implement a Xenon lamp aging test to see the elongation at break and time duration of the materials. Offshore fish cages can be floating, submerged or submersible. The nets used in the cages can be rigid or flexible. Rigid nets may be created by using a flexible net attached to a stiff framework to distend it, or a rigid metal net that will maintain its original shape regardless of the waves. In this paper, the focus is on gravity cages (Figure 1), which are most used for intensive aquaculture. This type of net cage usually consists of a mooring system, a jumping net to prevent fish escaping, a plumb fixed directly or indirectly to stretch the net, and a floating collar to provide buoyancy and attachment $[1,2]$.
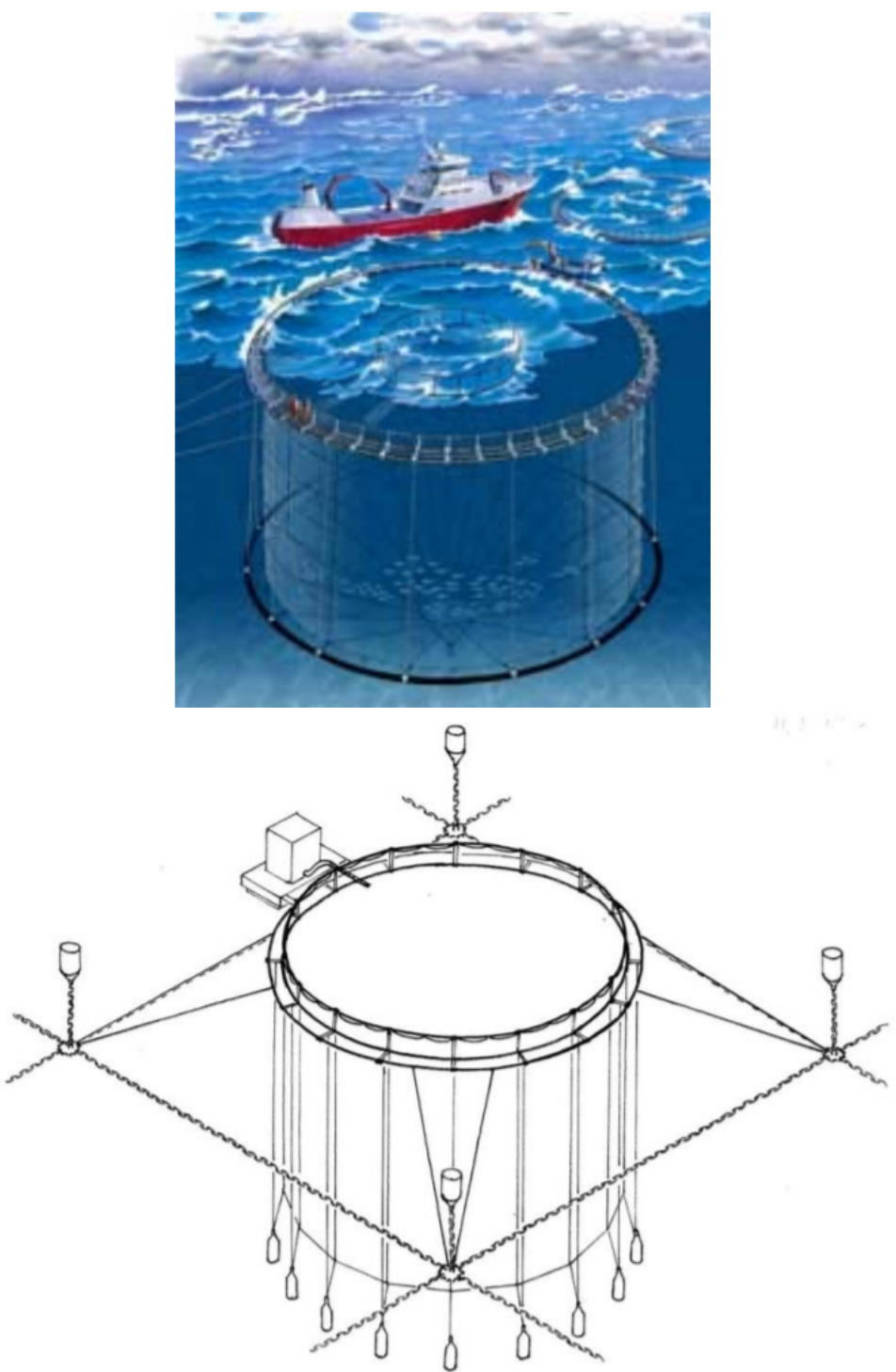

Figure 1 - Schematic diagram of the gravity cages. [2] 
The most frequently used fish cage systems in Norway are gravity cages, which rely on buoyancy and weights to hold their shape and volume as shown in Figure 1 [2].

The introduction of the Norwegian standard NS 9415 in 2003 resulted in legal requirements for strength analysis of fish farms. Up until then, all net cages had been dimensioned using trade standards based on empirical data. NS 9415 requires strength analysis to validate the dimensioning of large net cages and net cages subjected to large environmental loads [3].

Net cages are formed out of a system of ropes and netting that can be constructed in various shapes, sizes and materials. The net cages are designed to transfer and carry all major forces through the ropes. The net cage is also supported by the mooring system that keeps the farm in a fixed position and to avoid transfer of excessive forces to the net cage. It is important to take account for the loads from current, waves, weights and handling of the net when dimensioning the net cage. In the past, materials such as cotton and flax were used for the nets. These materials become heavy in the water and their strength is rapidly reduced; in addition, they are not very durable. Nowadays, synthetic plastic materials such as polyamide (PA, nylon) predominate. This material is cheap, strong and not too stiff to work with [1]. The last decade, other materials like PET-wire (Polyethylene terephthalate) have also been taken into use. PET-wire nets are semi-rigid and require less weight to keep the nets in place. The benefits of PET-wire are that it offers more protection against storm damage and predators like seals. Stronger materials also enable the net to maintain its shape better and may have a longer life span. This results in reduced deformation and drag, so the risk of rifts and other damage from adjacent equipment is reduced. PET-wire nets also have a reduced overall weight displacement compare to a cage, which means less load on the mooring system and reserve buoyancy for the cages. According to AkvaGroup ${ }^{\circledR}$, the tensile strength of the EcoNet PETwire is superior to Nylon and retains a high tensile strength for decades both below and above water, see Figure 2 [4].

However, the traditional nylon is a cheaper material, even though PET-wire may have a longer lifetime. PET-wire also weighs more, which can complicate the handling of large nets. Handling, together with other human errors and structural errors, are highlighted as some of the main challenges when it comes to fish escaping [5].

Net handling presents a major part of the total workload on a sea cage farm and requires specialized equipment. Marine fouling is a problem for sea cages, and the degree of fouling can be reduced by having the mesh size as large as possible. One or two sizes are typically used per year, but this depends on fish growth rate and species [1]. On more fouling-exposed sites, the nets may have to be changed more frequently. Changing the nets is heavy work and may require cranes to safely lift the nets during harvesting and cleaning to prevent rifts and other failures that may lead to escape. Netting made from stronger materials like PET-wire may stay in the water until it is damaged and can remain intact if a single wire is cut. According to AkvaGroup ${ }^{\circledR}$, the mesh shape will still be relatively stable with little effects on the structural strength. You can also do maintenance work like cleaning or antifouling on PETwire nets while submerged, which greatly reduces the risk of net damage because of net handling [4].

The hydrodynamic loads acting on a net cage depends on the solidity of the netting material. The solidity ratio $\left(S_{n}\right)$ is used to describe how 'tight' a net is and is defined as the ratio between the area covered by the twines in the net and the total area of the net [1]. 


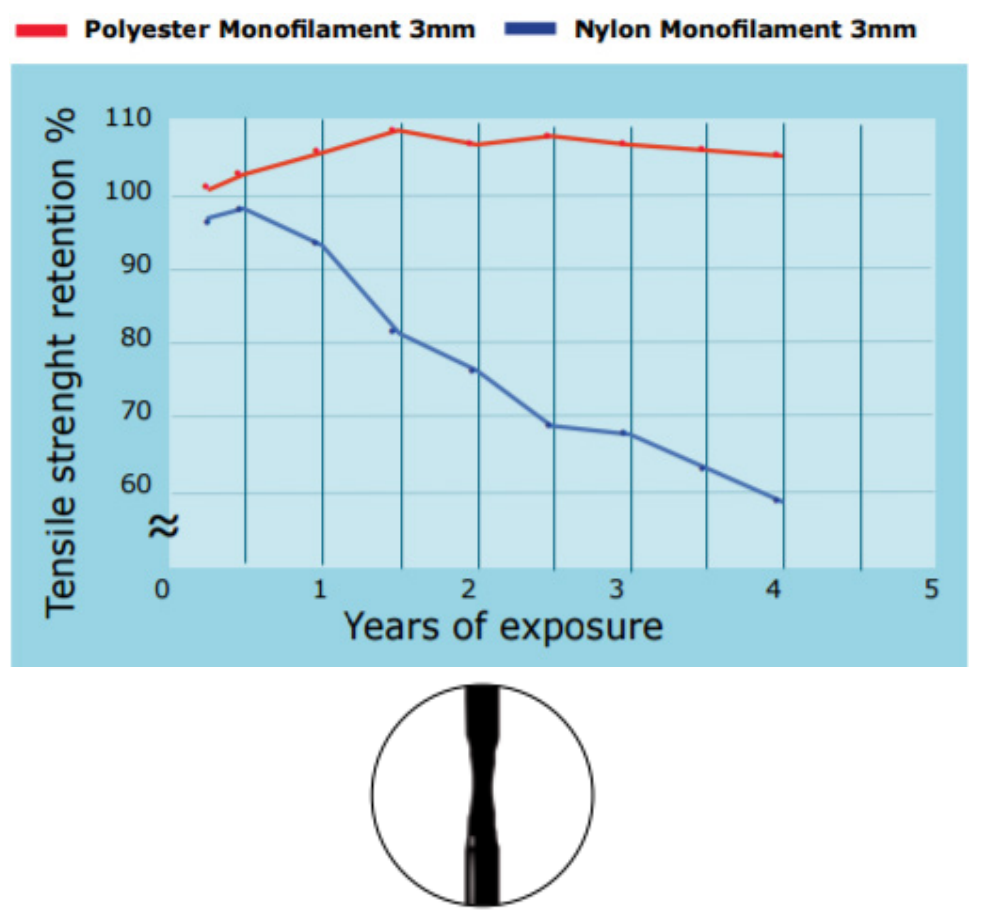

If overloaded, EcoNet stretch about $60-70 \%$ before it finally breaks.

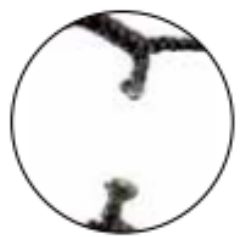

In comparison, nylon stretch about $40 \%$ before it finally breaks.

Figure 2 - Tensile strength retention of PET-wire and Nylon. [4].

$$
S_{n}=2 \cdot \frac{\text { Twine diameter }}{\text { Length of mesh side }} \text { or } \frac{\text { Twine area }}{\text { Total area }}
$$

This relation is important when we want to find the resistance against the water flow through and around the net, which again determines the hydrodynamic loads acting on the cage. The solidity will increase because of fouling on the net, which leads to an increase in the covered area and reduces the oxygen supply for the fish. Algae growth can also increase bacterial loads and cause diseases and stress. The marine fouling can be removed by using filtered high-pressure seawater.

Research into the mechanical performance of nets has a long history. It progresses along two major lines: experimental studies (sometimes combined with in-situ observations), and 
analytical/ numerical studies [6]. Usually, aquaculture suppliers like Aqualine ${ }^{\circledR}$ use a combination of both, where they build a prototype and place it in a water pool that generates waves for the final testing.

Modelling the hydrodynamic loads acting on a net cage is challenging due to hydroelasticity, i.e., fluid-structure interaction between moving sea-water and the flexible net [3]. The non-linear effects, detailed geometry and dynamic loads involved when analyzing a net cage makes detailed numerical modelling both complex and time-consuming. Although computational power has increased immensely during the past decades, a full-scale analysis of aquaculture net cages using CFD methods is still a challenge today because the net consists of thousands of thin twines. As simulation methods for finite element methods become more advanced, the detailed engineering analysis of the nets can contribute to improving the design, performance and reliability of the net cages. As the current state-of-the-art stands now, an analysis involving a complete fluid-structure interaction (FSI) model (coupling of CFD and FEA) is complex and extremely demanding on computational resources, and therefore there is ongoing work to verify and develop CFD methods for flow around net structures [7].

This paper presents a study of aquaculture net cages made of Nylon PA6, PET-wire, and polyurethane using fluid structure interaction (FSI) simulations using ANSYS ${ }^{\circledR}$. In this study, a piece of net is considered instead of a complete net cage.

\section{MODELLING OF AQUACULTURE NET CAGES}

Load models for net cages are typically based on Morison's equation, 2D panel tow-tests and so-called screen models [3,8]. Tsukrov, et al. [6] proposed a consistent one-dimensional net element to be used in the finite element method to model the dynamic response of net panels to open ocean environmental loading. The net panel refers to a section of netting between supports, see Figure 7. The focus of [6] is centered on the numerical modelling of deformation and overall dynamic behavior of nets subjected to wave and current loading. The simulations were implemented in the AQUA-FE program that is developed at the University of New Hampshire. This is an advanced computer design and analysis tool to model the dynamic response of partially or completely submerged structures in an ocean environment [6].

Moe et al. [7] modelled a net cage using 3-D truss elements that represented several parallel twines. Sub-elements allowed the trusses to buckle in compression. The truss elements were given the combined properties of the represented twines, i.e. the cross-section area of the truss element was equal to the sum of the cross-section area of the represented twines. Moe et al. [7] present a method for numerical strength analysis of net cages in constant uniform current verified for limited solidity, deformations and current velocities, applying Morison's equation to calculate loads on the deformed net cage. Strength analyses were performed using the finite element method software ABAQUS Explicit.

Another applied approach presented by Zhao et al. [9] was to model the net as a porous medium. Here, the solidity of the net is decided by the porosity to make the structure affect the flow pattern in the fluid domain. The finite volume method was used to solve the governing equations of the numerical model using ANSYS ${ }^{\circledR}$ Fluent 6.3.

When dimensioning a net cage, the net should be constructed to model the drag, buoyancy, inertial and elastic forces exerted on the netting by current and waves. On ordinary sites, it will be the current that causes the highest forces, while on more exposed sites the wave forces 
will be considerable [1]. The resulting forces on a moving body in an unsteady viscous flow can be determined using the Morrison equation, which is a combination of an inertial term and a drag term:

$$
\boldsymbol{F}=\boldsymbol{F}_{D}+\boldsymbol{F}_{I}
$$

where the drag force is given by:

$$
\boldsymbol{F}_{D}=\frac{1}{2} \rho_{w} C_{D} A_{r e f} \boldsymbol{U}_{R}\left|\boldsymbol{U}_{R}\right|
$$

where $\rho_{w}$ is the water density, $C_{D}$ is the drag coefficient, $A_{r e f}$ is the reference area and $\boldsymbol{U}_{R}=\boldsymbol{U}-\boldsymbol{V}_{B}$ is the relative flow velocity, $\mathrm{U}$ is the flow velocity and $\boldsymbol{V}_{B}$ is the body velocity. And the inertia force is given by:

$$
\boldsymbol{F}_{I}=\rho_{w} C_{a} V \dot{\boldsymbol{U}}_{R}+\rho_{w} V \dot{\boldsymbol{U}}
$$

where $C_{a}$ is the added mass coefficient and $\mathrm{V}$ is the body volume [10]. Bold letters denote vectors.

\section{FLUID-STRUCTURE INTERACTION (FSI) MODELLING}

A fluid-structure interaction (FSI) simulation is a coupled fluid dynamics (CFD) and structure mechanics (FEM) case where we want to see how the fluid flow exerts the hydrodynamic forces on the net. The fluid flow calculates and passes flow fields from the CFD to the FEM code. Transmission of variables from CFD to another solver is complex hence requires due diligence [11-13]. The fluid elements in the fluid flow field will each undergo three different effects: translation, deformation and rotation. The hydrodynamic forces exerted on the net will deform and/ or translate the net before the deformed/translated net imparts the velocity to the fluid domain and changes its shape, as well as the fluid flow. In an FSI analysis, we study the interaction between two different physical phenomena, implemented in separate analyses/ solvers. There are different modes of FSI modeling: rigid body FSI, one-way FSI [14] and two-way FSI [15]. With the rigid body FSI, we assume that there is no deformation in the solid structure and only the motions of the structure in the fluid are considered. Two-way FSI is done in an iterative loop, i.e. the results of the CFD analysis at the fluid-structure interface are transferred to the mechanical model and applied as loads. Within the same analysis, the subsequently calculated displacements at the fluid-structure interface are mapped back to the CFD analysis. The loop continues until convergence is found, and often involves the changes to the mesh of the model. As we are working with thin twines that divide the water around the interface down into small elements, a two-way FSI with several twines will be too demanding for the computational resources available. Because of this, a one-way FSI model is used for this study. In addition, a piece of net is modelled instead of the complete cage to compare the performance of Nylon PA6, PET-wire, and polyurethane materials [16]. 


\section{FLUID-STRUCTURE INTERACTION (FSI) MODEL OF AQUACULTURE NET PANEL}

The net panel is modelled as three-dimensional cylinders in ANSYS ${ }^{\circledR}$ DesignModeler geometry (Figure 3). The net panel was created with the following properties:

Table 1 - Geometric properties of the net panel.

\section{Length of mesh side}

Twine thickness

Beam thickness

Twine cross-section area

\section{$54.4 \mathrm{~mm}$}

$3 \mathrm{~mm}+50 \%$ fouling $=4.5 \mathrm{~mm}$

$4 \mathrm{x}$ Twine thickness $=18 \mathrm{~mm}$

$254.47 \mathrm{~mm}^{2}$

*Note that the length of mesh side is twice the maximum length presented [17].

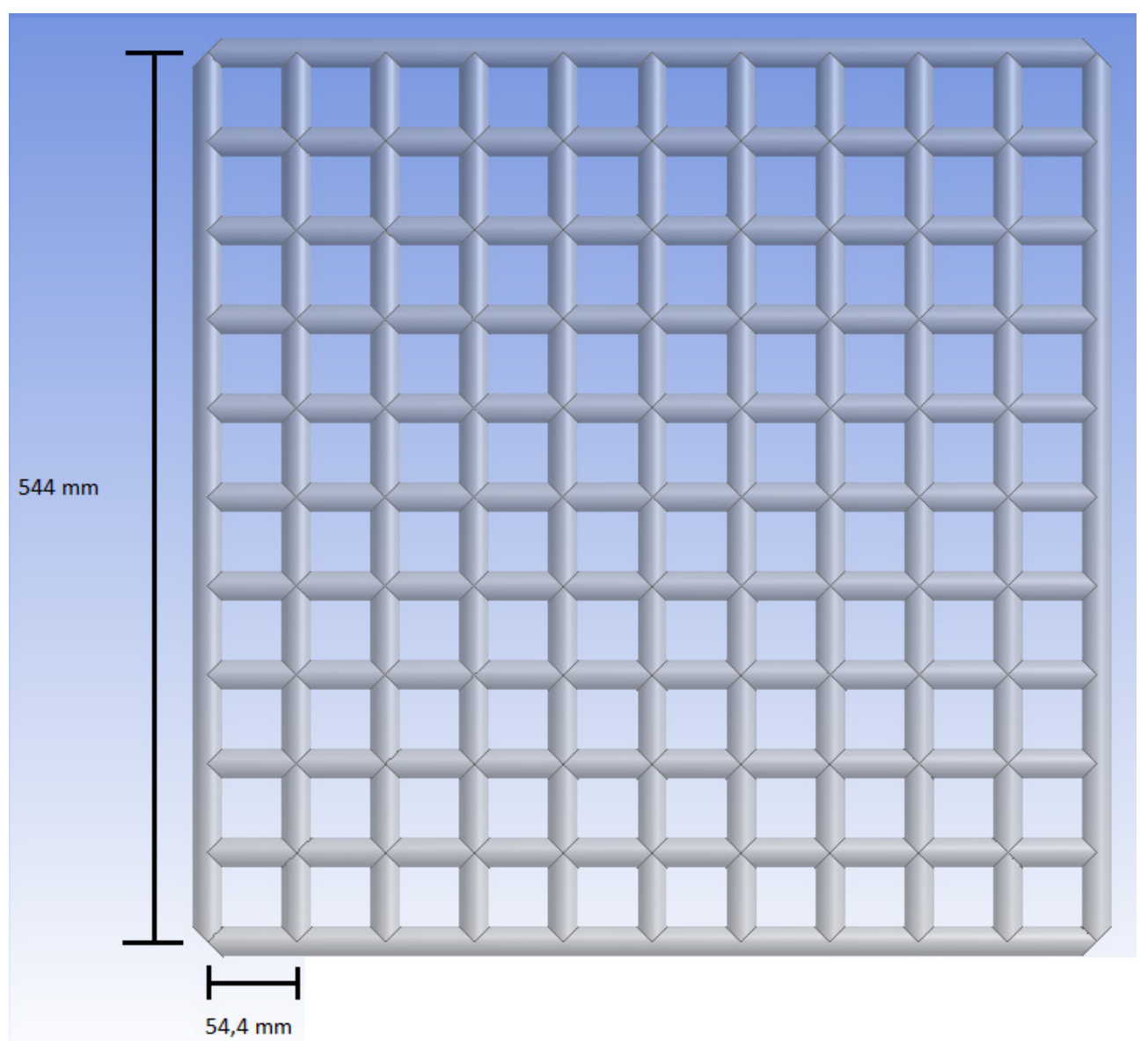

Figure 3 - Illustration of the net panel geometry. Bounding box length $x=18 \mathrm{~mm}$, $\mathrm{y}$ and $\mathrm{z}=562 \mathrm{~mm}$. 
The mesh is generated with a CFD physics preference in the Fluent solver. Element sizing is decided by the size function proximity and curvature, with a medium relevance center, slow transition and a fine span angle center. The quality target skewness is by default 0.9 , with medium smoothing. While meshing the water domain, the net panel is suppressed. Still, we can see an increased number of elements due to the fluid-structure interface which consists of 194 faces with a surface area of $0.54698 \mathrm{~m}^{2}$ and a volume of $0.0026527 \mathrm{~m}^{3}$. If the structure is not subtracted from the water domain, the water domain would just be a square mesh. The square mesh would have a small number of elements compared to the water domain with the fluid-structure interface. Another point to add is that, if the structure is not subtracted from the water, the water flow would not flow through the net.

The inlet is defined so that the flow travels in the direction of the positive $\mathrm{x}$-axis (Figure 4). The corners at each edge of the net panel are cut into one face to reduce the number of elements generated by meshing, as the circular end-points of the cylinders would further divide the water elements around the interface. Then, the Boolean unite operation is used to assemble all cylinders into one body; the net panel. The water domain is made in a rectangular shape with dimensions $4000 \times 2544 \times 1594 \mathrm{~mm}$ to make it symmetric around each side of the net, except in the $\mathrm{x}$-direction where there is more space after the netting section to see the

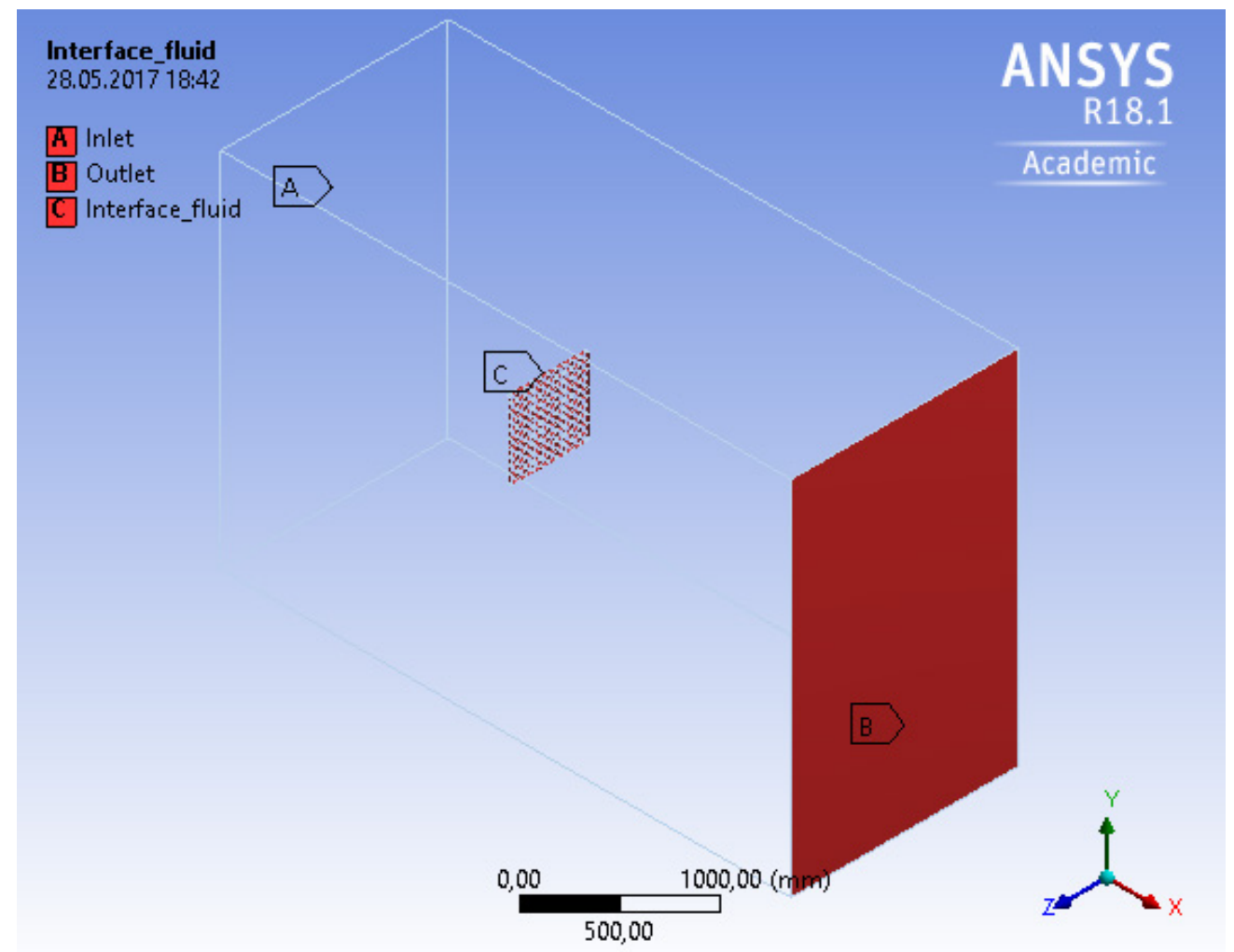

Figure 4 - Named selections of the geometry. The remaining walls around the water domain is defined as free surfaces. 
behavior of the flow lines. If the walls of the water domain are too close to the net panel, the flow lines will swirl more after deflection, which will affect the results. Finally, the Boolean subtract operation is used to subtract the net panel from the water domain, so ANSYS ${ }^{\circledR}$ Fluent knows there is a solid body inside the water in Fluent meshing. If the net is not subtracted from the water domain, there is no CFD surface to import the pressure from Fluent to structural.

The material properties are defined for each of the materials in engineering data, with Young's Modulus, Poisson's ratio and density (which must be specified when inertia forces are involved). The material properties used in this study are retrieved from $[18,19]$ and [20].

Boundary and loading conditions are specified on the net panel as shown in Figure 5. The gravity acceleration changes due to the buoyancy of water. The fixed support boundary condition is located at the top and at the two cut corners at the topside of the net panel and keeps the selected faces from moving or deforming. The global acceleration boundary condition for the net panel is calculated by the buoyancy of the net and the gravity. The acceleration changes with the density of the materials used and is defined in the positive zdirection in the global coordinate system. The imported pressure is loaded to the net panel geometry by specifying the 194 faces of the net panel, and the fluid-structure interface is defined as the CFD surface (Figure 6).

Table 2 - Material properties of unreinforced Nylon, glass fiber reinforced Nylon, PET, Polyurethane.

\begin{tabular}{|c|c|c|c|c|c|c|}
\hline $\begin{array}{l}\text { Base } \\
\text { polymer }\end{array}$ & Description & $\begin{array}{l}\text { Specific } \\
\text { gravity } \\
{[-]}\end{array}$ & $\begin{array}{l}\text { Density } \\
{\left[\mathrm{kg} / \mathrm{m}^{3}\right]}\end{array}$ & $\begin{array}{l}\text { Tensile } \\
\text { Modulus } \\
\text { [MPa] }\end{array}$ & $\begin{array}{l}\text { Global } \\
\text { acceleration. } \\
{\left[\mathbf{m} / \mathbf{s}^{2}\right]}\end{array}$ & $\begin{array}{l}\text { Mass of } \\
\text { net } \\
\text { panel } \\
{[\mathrm{kg}]}\end{array}$ \\
\hline Nylon PA6 & $\begin{array}{l}\text { Unreinforced } \\
\text { base resin }\end{array}$ & 1.13 & 1158 & 2758 & 1.27 & 3.07 \\
\hline Nylon PA6 & $\begin{array}{l}30 \% \text { glass fiber } \\
\text { reinforced, heat } \\
\text { stabilized }\end{array}$ & -- & 1350 & 9800 & 3.11 & 3.58 \\
\hline $\begin{array}{l}\text { Polyethylene } \\
\text { Terephthalate } \\
\text { (PET) }\end{array}$ & $\begin{array}{l}30 \% \text { glass fiber } \\
\text { reinforced }\end{array}$ & 1.56 & 1599 & 11032 & 5.49 & 4.24 \\
\hline $\begin{array}{l}\text { Ester-based } \\
\text { thermoplastic } \\
\text { Polyurethane } \\
\text { elastomer }\end{array}$ & $\begin{array}{l}30 \% \text { glass fiber } \\
\text { reinforced }\end{array}$ & 1.44 & 1476 & 3103 & 4.31 & 3.91 \\
\hline
\end{tabular}




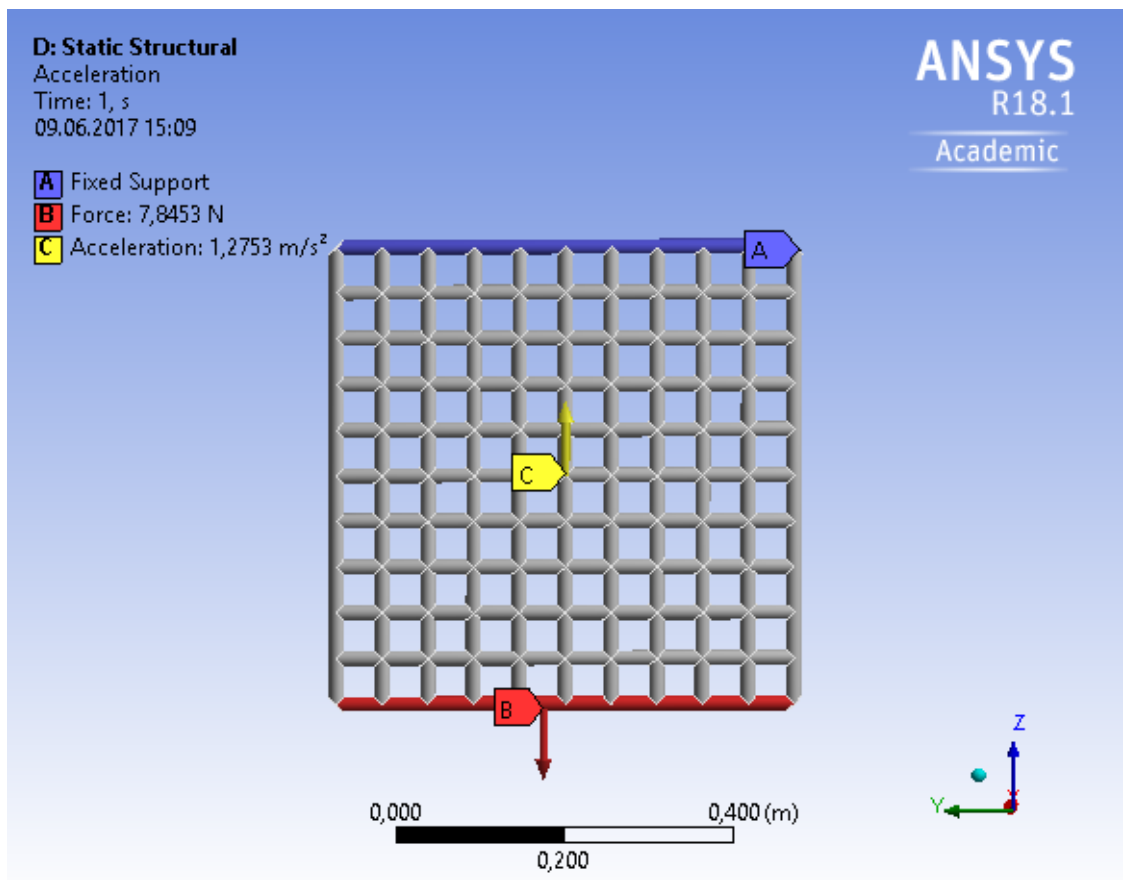

Figure 5 - Boundary and loading conditions specified for the net panel.

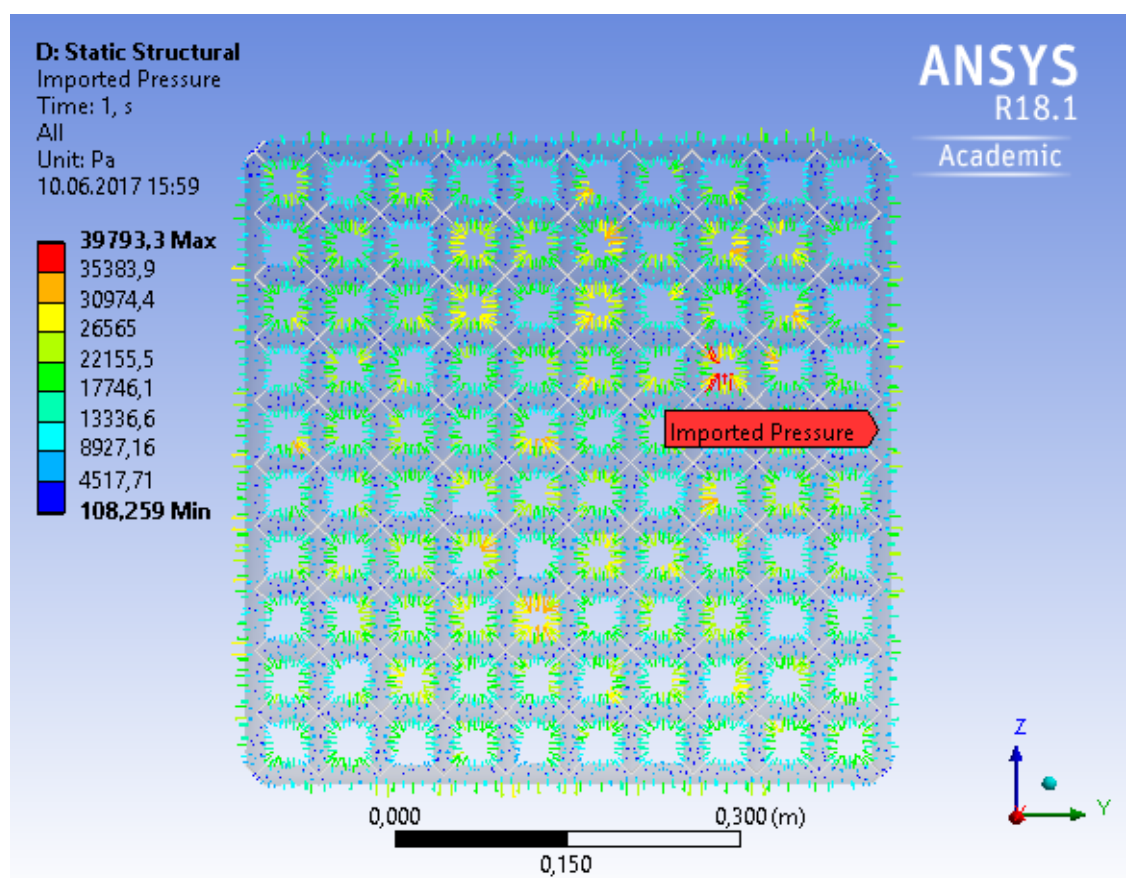

Figure 6 - Imported pressure with a water velocity of $5.0 \mathrm{~m} / \mathrm{s}$, seen from the outlet. 


\section{RESULTS AND DISCUSSION}

Flow field vectors and streamlines around the net panel are shown in Figures 7 and 8.

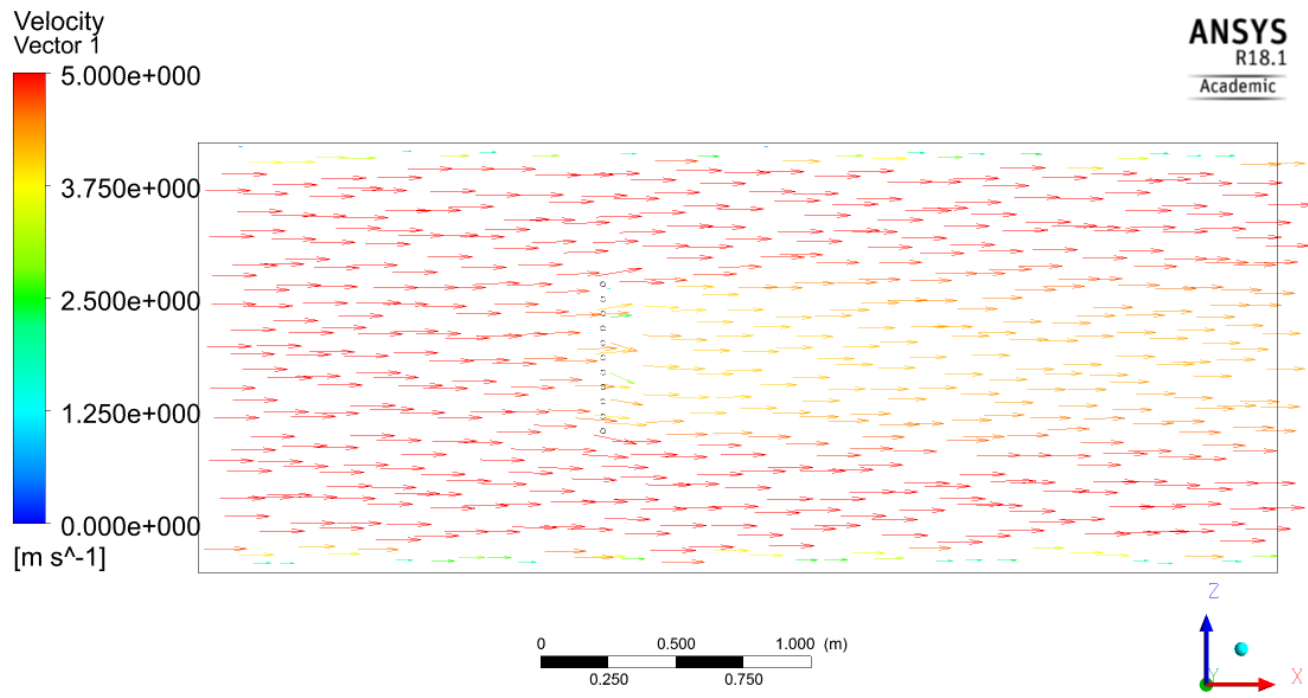

Figure 7 - Water velocity vectors with a water velocity of $5.0 \mathrm{~m} / \mathrm{s}$.

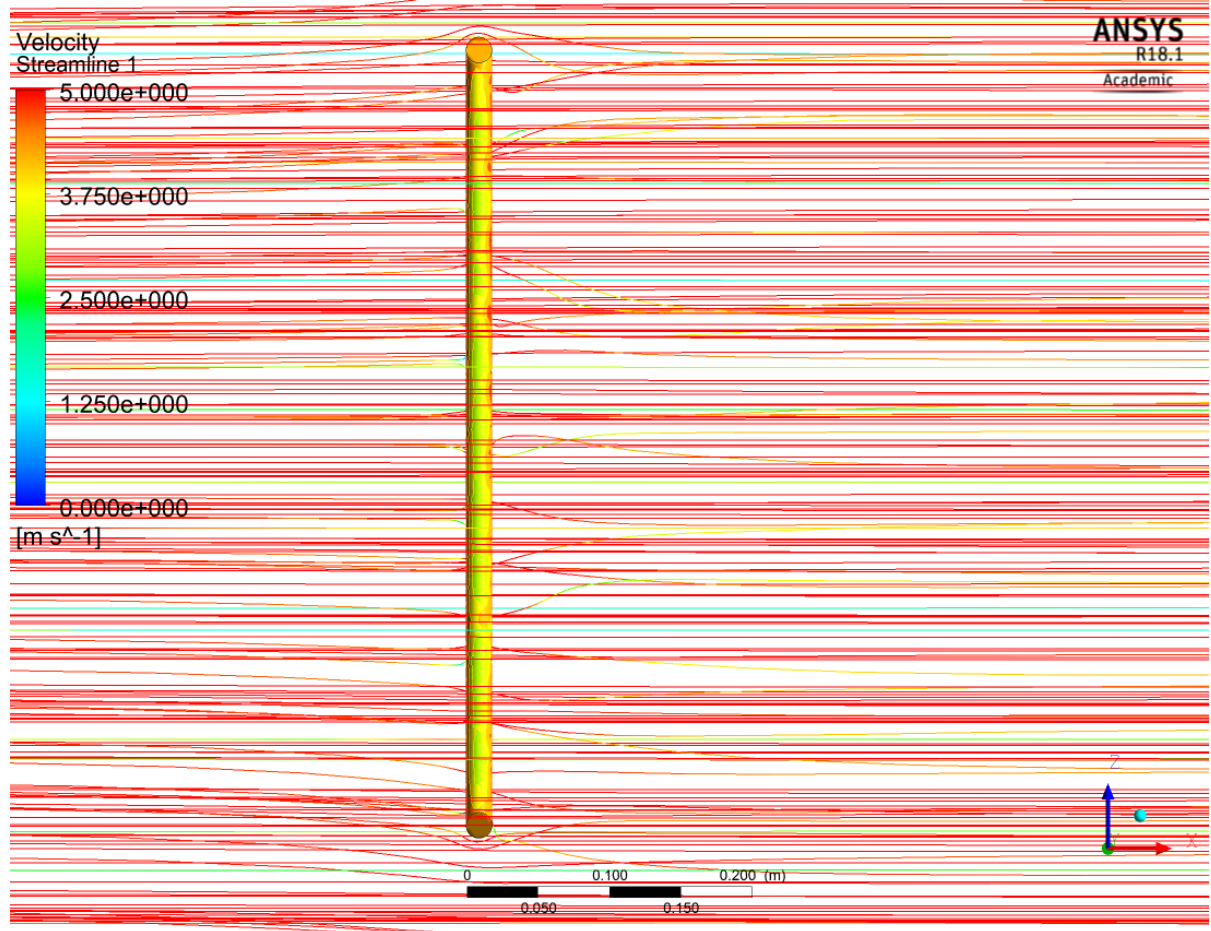

Figure 8 - Velocity streamlines deflected by the net panel with a water velocity of $5.0 \mathrm{~m} / \mathrm{s}$. 
Deformation of the net panel due to the pressure exerted by the flow field is shown in Figure 9.

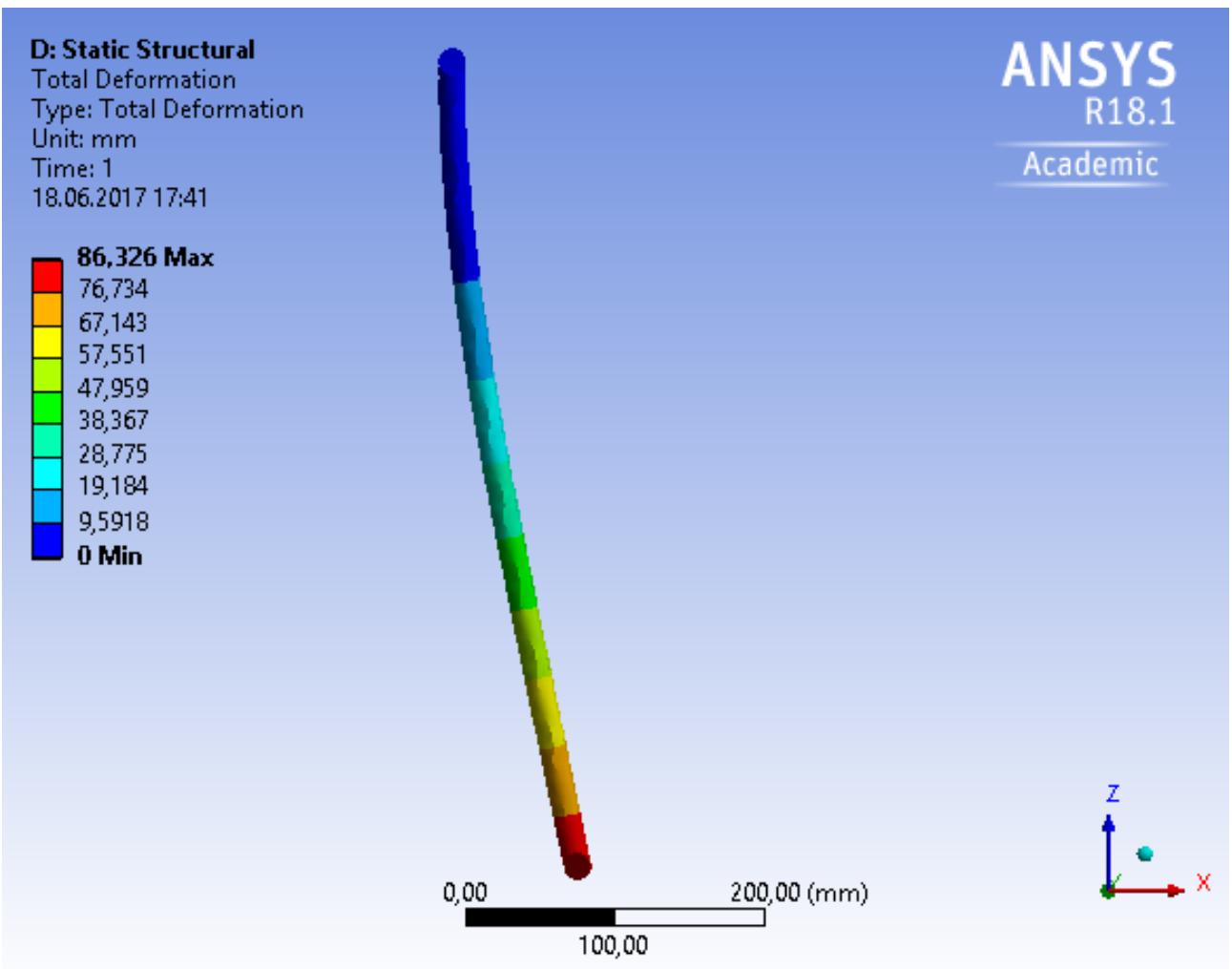

Figure 9 - Total deformation of the unreinforced Nylon PA6 net panel with a water velocity of $5.0 \mathrm{~m} / \mathrm{s}$ (true scale).

Table 3 below shows the maximum total deformation of the net panel with different materials and velocity.

\begin{tabular}{|c|c|c|c|c|c|}
\hline \multirow{2}{*}{$\begin{array}{l}\text { Max. total } \\
\text { deformation }[\mathrm{mm}]\end{array}$} & \multicolumn{5}{|c|}{ Velocity } \\
\hline & $0.1 \mathrm{~m} / \mathrm{s}$ & $0.5 \mathrm{~m} / \mathrm{s}$ & $1.0 \mathrm{~m} / \mathrm{s}$ & $2.0 \mathrm{~m} / \mathrm{s}$ & $5.0 \mathrm{~m} / \mathrm{s}$ \\
\hline $\begin{array}{l}\text { Nylon PA6 } \\
\text { unreinforced }\end{array}$ & 0.059 & 1.057 & 3.875 & 15.05 & 86.32 \\
\hline $\begin{array}{l}\text { Nylon PA6 } \\
\text { reinforced }\end{array}$ & 0.016 & 0.2987 & 1.091 & 4.236 & 26.08 \\
\hline PET-wire & 0.014 & 0.2652 & 0.9689 & 3.763 & 23.21 \\
\hline Polyurethane & 0.052 & 0.9383 & 3.441 & 13.38 & 77.45 \\
\hline
\end{tabular}

Equivalent (von-Mises) stress of net panel due to the flow field is shown in Figure 10. 


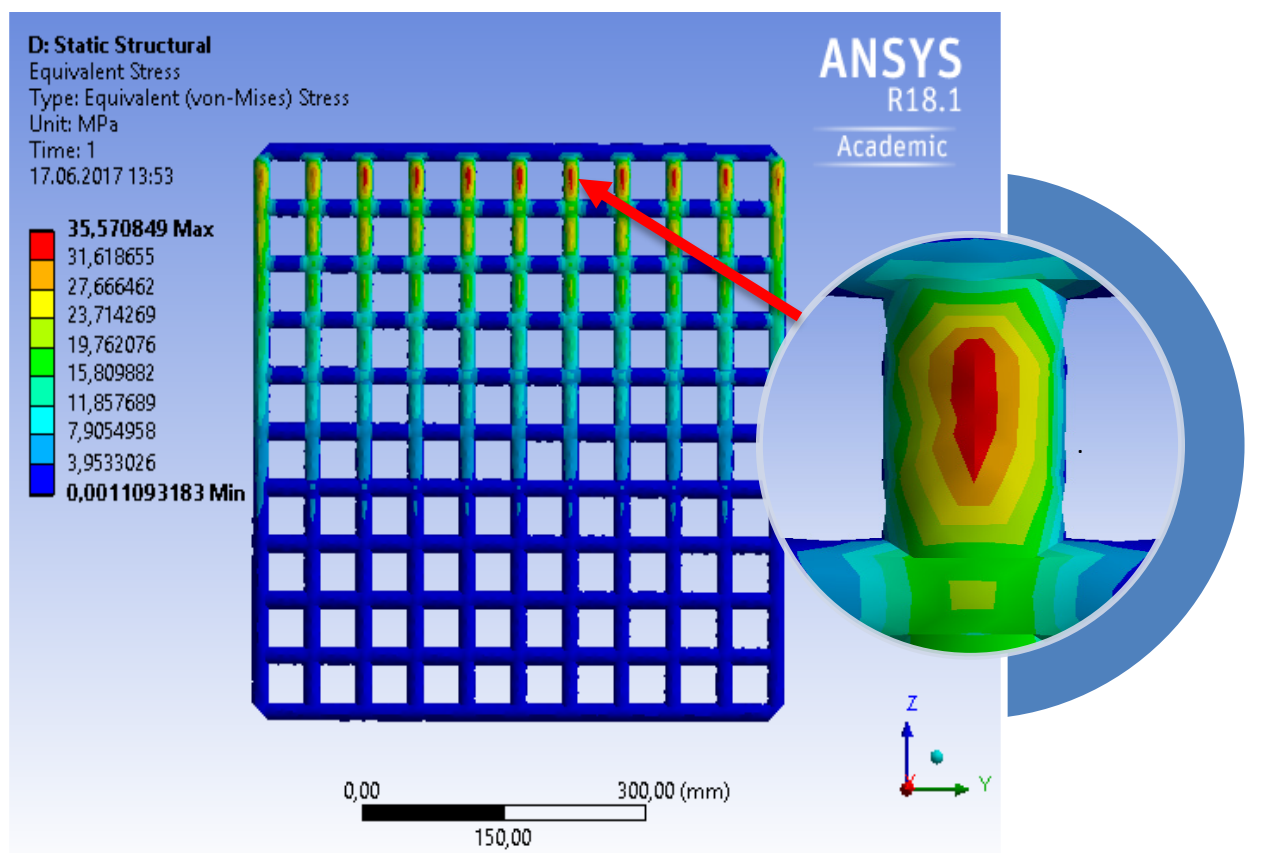

Figure 10 - Equivalent stress of the PET-wire net panel with a water velocity of $5,0 \mathrm{~m} / \mathrm{s}$, seen from the outlet.

The maximum equivalent (Von Mises) stress of the net panel with the different materials and velocities are listed in Table 4, below.

Table 3 - Maximum equivalent stress of the net panel.

\begin{tabular}{lccccc}
\hline Max. Equivalent stress $[\mathrm{Pa}]$ & \multicolumn{5}{c}{ Velocities } \\
\cline { 2 - 6 } & $\mathbf{0 . 1} \mathbf{~ m} / \mathbf{s}$ & $\mathbf{0 . 5} \mathbf{~ m} / \mathbf{s}$ & $\mathbf{1 . 0} \mathbf{~ m} / \mathbf{s}$ & $\mathbf{2 . 0} \mathbf{~ m} / \mathbf{s}$ & $\mathbf{5 . 0} \mathbf{~ m} / \mathbf{s}$ \\
\cline { 2 - 6 } Nylon PA6 unreinforced & 27318 & 408514 & 1477228 & 5739321 & 33924880 \\
Nylon PA6 reinforced & 29900 & 412146 & 1481051 & 5741841 & 35519847 \\
PET-wire & 34135 & 416246 & 1484826 & 5746084 & 35570849 \\
Polyurethane & 31810 & 412426 & 1480195 & 5743851 & 34114041 \\
\hline
\end{tabular}

Table 4 - Safety factor for the net panel with different materials.

\begin{tabular}{lll}
\hline $\begin{array}{l}\text { Safety factors calculated from the } \\
\text { max. equivalent stress at } \mathbf{5 . 0} \mathbf{~ m} / \mathbf{s}\end{array}$ & $\begin{array}{l}\text { Ultimate tensile } \\
\text { strength }[\mathbf{M P a}]\end{array}$ & Safety factor, $\boldsymbol{F}_{\boldsymbol{s}}=\frac{\boldsymbol{s}_{\text {limit }}}{\boldsymbol{\sigma}_{\boldsymbol{e}}}$ \\
\hline Nylon PA6 unreinforced & 76 & 2.24 \\
Nylon PA6 reinforced & 180 & 5.07 \\
PET-wire & 152 & 4.27 \\
Polyurethane & 72 & 2.11 \\
\hline
\end{tabular}


In the real world, components such as tidewater current, wind-induced surface current, an outbreak from the coastal current and spring flood because of snow and ice melting [21] would all contribute to the total current overview. In addition, the angle of attack of the water would most likely not be set perpendicular to the net panel. The fixed supports that hold the top faces in a fixed position during loading would also be able to move a bit in a real situation. These are all factors that could change how a net will deform in the real world.

\section{CONCLUSION}

Based on the results of this study, all the materials could be used for net cages. As mentioned in the introduction, fish welfare depends on a certain minimum volume within the net cage. For weather-exposed locations with higher flow velocities, the stronger materials like reinforced nylon PA6 and PET-wire would better enable a net to maintain its shape. According to the Norwegian Standards NS9415, the breaking strength of the net pens below surface must not fall below $65 \%$ of the initial strength of the net. In areas where there are less environmental loads in the form of currents and waves, economic analyses should be performed to see what material is the most reasonable by considering the material costs and the total life span of the nets. The materials must also be analyzed for toxicity. The toxicity affects both the fish welfare as well as the marine ecosystem.

\section{REFERENCES}

[1] Lekang, O., Aquaculture Engineering, Second Edition. 2013: John Wiley \& Sons, Ltd.

[2] I.J. Aarhus, e.a., Kartlegging av ulike teknologiske løsninger for å møte de miljømessige utfordringene i havbruksnæringen. 2011, SINTEF.

[3] Moe-Føre, H., et al. Structural response of high solidity net cage models in uniform flow. Journal of Fluids and Structures, 65 2016; 180-195].

[4] AkvaGroup. Cage Farming Aquaculture. 2016

[5] T. Thorvaldsen, e.a., The escape of fish from Norwegian fish farms: Causes, risks and the influence of organisational aspects, in Marine Policy. 2015, Elsevier.

[6] I. Tsukrov, e.a. Finite element modeling of net panels using a consistent net element. Ocean Engineering, 30(2) 2003 [cited 251-271]

[7] Moe, H., A. Fredheim, and O.S. Hopperstad. Structural analysis of aquaculture net cages in current. Journal of Fluids and Structures, 26(3) 2010; 503-516].

[8] Khawaja, H., Application of a 2-D approximation technique for solving stress analyses problem in FEM. The International Journal of Multiphysics, 2015. 9(4): p. 317-324.

[9] Zhao, Y.-P., et al. Numerical simulation of the flow around fishing plane nets using the porous media model. Ocean Engineering 2013 [cited 62; 25-37].

[10] Potyagaylo, S. and S.G. Loizou. Online Adaptive Geometry Predictor of Aquaculture Fish-Nets. 2014;

[11] Khawaja, H.A., Sound waves in fluidized bed using CFD-DEM simulations. Particuology, 2018. 38: p. 126-133.

[12] Khawaja, H., et al., Quantitative Analysis of Accuracy of Voidage Computations in CFD-DEM Simulations. The Journal of Computational Multiphase Flows, 2012. 4(2): p. 183-192. 
[13] Baryshev, G., H. Khawaja, and M. Moatamedi, Optimization of Particle Search Algorithm for CFD-DEM Simulations. The Journal of Computational Multiphase Flows, 2013. 5(3): p. 223-230.

[14] Khawaja, H.A., et al., Study of CRFP Shell Structures under Dynamic Loading in Shock Tube Setup. Journal of Structures, 2014. 2014: p. 6.

[15] Khawaja, H.A., et al., Fluid Solid Interaction Simulation of CFRP Shell Structure. Mathematics in Engineering, Science and Aerospace (MESA), 2017. 8(3): p. 311-324.

[16] Perng, Y.-Y., Modeling Fluid Structure Interactions. 2011, ANSYS, Inc.

[17] Harboe, T. and O.F. Skulstad. Maskeåpning, rømningsfare og fiskevelferd. 2014

[18] goodfellow.com. Polyamide - Nylon 6 (PA 6) - Material Information. 2017; Available from: http://www.goodfellow.com/E/Polyamide-Nylon-6.html.

[19] professionalplastics.com. Mechanical Properties of Plastic Materials. 2017

[20] Casanova, C. and W. Dwikartika. Modeling of Aquaculture PET Net with the Use of Finite Element Method. 2013

[21] Norge, S., Marine fish farms. Requirements for site survey, risk analyses, design, dimensioning, production, installation and operation., in Site surveys: General. 2009, Standard Norge: standard no. p. 21. 
112 